\title{
CLOUD MIGRATION STRATEGY: REVIEW \& RECOMMENDED STRATEGY PROCESS MODEL FOR COMMUNICATION AND IT MINISTRY OF AFGHANISTAN
}

\author{
Muhammad Aslam Hemmat Qachmas \\ Balkh University \\ Balkh, Afghanistan \\ Sayed Muhammad Yonus Saiedy \\ Bakhtar University \\ Kabul, Afghanistan
}

Abstract- With regard to the increasing spread of information technology in the world, access to this technology is of great importance. Having an appropriate process for migrating, identifying and ranking activities to prepare and perform the migration design in the organization, prevents the failure of the performance in organizations. Today, there are lots of migration processes in review of literature and this will confuse the managers to choose the most appropriate process for their organization. This article studies the presented processes of migration to the cloud computing environment by presenting novel factors. It also attempts to introduce an appropriate framework to select and model the most efficient process on migration to the cloud computing environment. So that organizations do not have a concern to choose the best migration process and IT managers are able to select the appropriate process for their organizations quickly and with no confusion. This paper is intended to introduce a migration strategy process model which best suits for the current situation of communication and IT ministry of Afghanistan. This paper contains an introduction on cloud computing and cloud migration, literature review of the related works done on migration strategies, also includes some information about Afghanistan communication \& information technology ministry, A methodology of selecting and modeling recommended migration strategy, modeling the recommended cloud migration strategy process for Afghanistan communication \& IT ministry, conclusion and references list.

Keywords- Cloud Computing, Migration, Migration Strategy, communication \& IT Ministry.

\author{
Ali Mohammad Serat \\ Assist. Prof., Bakhtar University \\ Kabul, Afghanistan \\ Hafiz Muhammad Bilal \\ Assist. Prof., Bakhtar University \\ Kabul, Afghanistan
}

\section{INTRODUCTION}

Cloud computing is a model for enabling convenient on- demand network access to a shared pool of configurable computing resources (e.g., networks, servers, storage, applications and services) that can be rapidly provisioned and released with minimal management effort or service provider interaction (Alharthi, Alassafi, J Walters \& B Wills 2017). Cloud computing has been commonly used to the industry level because of the effective role in reducing the overall expenses and changing them to the operational costs (SABIRI, BENABBOU, MOUTACHAOUIK \& HAIN 2016).

The key concept of cloud computing is that you don't buy the hardware, or even the software, you need anymore, rather you rent some computational power, storage, databases, and any other resource you need by a provider according to a pay-as-you-go model, making your investment smaller and oriented to operations rather than to assets acquisition (Balasubramaniam, Deepa. 2018). The potential of cloud computing may include reducing IT costs while increasing productivity, scalability, and flexibility (Alharthi, Alassafi, Walters \&Wills, 2017). There are many cloud migration strategies suggested from academia and industry. For instance Chauhan's Methodology, REMICS, Tran's Methodology, Cloud-RMM, Strauch's Methodology, Zhang's Methodology, Oracle, ARTIST, Amazon, and Legacy-to-Cloud Migration Horseshoe (Gholami, Daneshgar \& Rabhi, 2018).

Cloud Computing is defined as the delivery of computing resources (hardware and software) as a service rather than a product, whereby resources are 


\section{International Journal of Engineering Applied Sciences and Technology, 2020 \\ Vol. 5, Issue 4, ISSN No. 2455-2143, Pages 73-81 \\ Published Online August 2020 in IJEAST (http://www.ijeast.com)}

provided to users as a metered service over the Internet (Alzoubaidi, 2016).

In this section it's really needed to understand some terms on cloud migration and types of cloud computing and services which are briefly concluded as follows:

\section{Cloud migration}

Cloud migration is the process of moving applications, services, codes and business logic deployed on the on premise infrastructure to cloud platforms with the aim of achieving significant improvement in performance, scalability and cost reduction (Kesavulu, Bezbradica \& Helfert, 2017).

Cloud migration is the process of partially or completely deploying an organization's digital assets, services, IT resources or applications to the cloud. The cloud migration process may involve retaining some IT infrastructure on-site (17. Pahl, C., \& Xiong, H. 2013).

The migration of legacy systems of one organization to Cloud Computing environments represents great advantages in the cost-benefits analysis (e.g. pay only for what it is used, less investment in hardware and technical maintenance, etc.) and growing opportunities for rapid adaptation to dynamic changes of the organization business market (Zalazar, A. S., Gonnet, S. M., \& Leone, H. P. 2015).

\section{Cloud computing services}

Cloud computing initially provides three main types of services; these are (Alzoubaidi, 2016 and Au, 2016):

a) Infrastructure as a Service (IaaS): All required hardware to run a business is provided by communications service providers and customers manage their application software.

b) Platform as a Service (PaaS): A user pays to the service provider to use their platform as their IT solution. For example, if a user needs E-mail system or database software for their business, they can use a third party's computing service that prove email and database solutions.

c) Software as a Service (SaaS): If a user needs to use a specific kind of software to get an output or to perform an analysis, then it is much cheaper to use that software service from a CSP rather than buying, installing and maintaining it.Fig. 1 shows the current Cloud Computing services that are currently provided by most major hardware and software brands, e.g., HP, DELL, Amazon, IBM, Google, and Microsoft, etc., (Alzoubaidi, A. R. (2016).

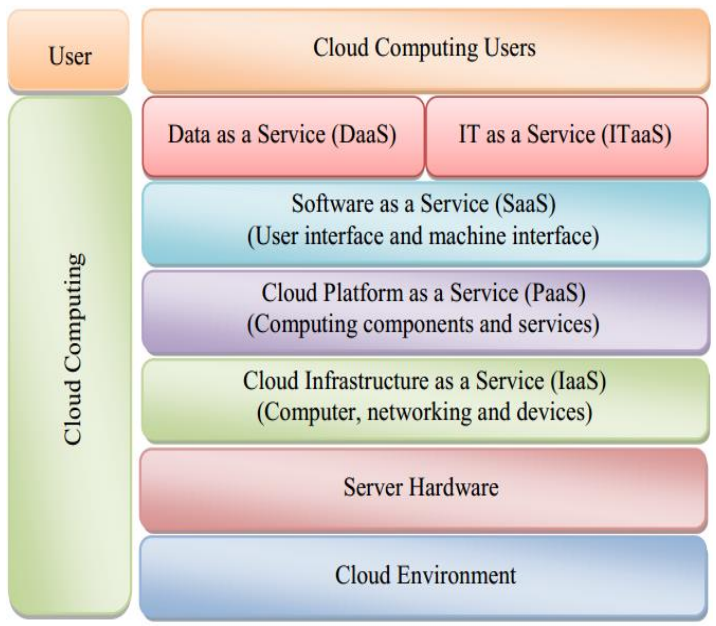

Fig. 1. Cloud Computing services.

\section{Cloud deployment models}

d) Private Cloud: This is a cloud infrastructure dedicated to a single organization or enterprise. It can be hosted and managed internally or externally. The benefits of a private cloud include tight security controls, customization and scale-up potential ([10] \& (Deepa.B, Srigayathri.S \& Visalakshi.S, 2018)).

e) Public Cloud: The so called public cloud is one that is generally provided over the Internet through service providers such as Amazon, Microsoft, or Google. While start-up costs are less than a private cloud, security and privacy is much less secure on public clouds ( $\mathrm{Au}, 2016)$.

f) Community Clouds: These cloud infrastructures can be shared by enterprises with common concerns. Trade associations, non-profits, small professional firms, etc. with similar security, legal and compliance issues may utilize this type of cloud (Aslam, Rahim, Watada \& Hashmani, 2018).

g) The Hybrid Cloud: Combine any of the above clouds and bind them together to expand deployment options. This can allow for "cloud bursting," in which an application runs in a private cloud but "bursts" to a public cloud when demand increases. The hybrid cloud allows you to keep your private cloud while also adding the additional storage and cost-effectiveness of a public cloud. For a real life example of how the NFL benefitted from the use of a hybrid cloud check out this article [10] and (Au, 2016).

\section{Cloud computing characteristics}

Based on these definitions, five essential characteristics are attributed to Cloud Computing (Zalazar, A. S., Gonnet, S. M., \& Leone, H. P. 2015): (a) On-demand self-service: Cloud consumers automatically access to Cloud resources according to 
their needs; (b) Broad network access: cloud resources are available in the network, and the access to resources is performed by different client platforms; (c) Resource pooling: Cloud provider resources are shared between multiple Cloud consumers, by using virtualization mechanism and tenancy; (d) Rapid elasticity: virtual and physical resources are added and released according to Cloud consumers demand; and (e) Measured service: Cloud systems automatically control and measure the services use in a transparent manner for all Cloud actors.

In this paper, the research achievements and application status on cloud migration is reviewed, a comprehensive analysis of existing migration methods is made and at the end the corresponding considerations of each respective strategy is identified. The research question for this research paper is "which strategy process model can be best deployed for current situation of Afghanistan communication and IT ministry?" and the objectives to reach the above research question are:

- Study the current situation of communication \& IT ministry of Afghanistan

- To recommend a strategy process model considering the current situation of communication \& IT ministry of Afghanistan by selecting the reviewed migration strategy models/ frameworks

The rest of this paper is organized as follows. In Section II, existing migration strategies are reviewed, and a classification is proposed. Section III there exist an introduction to the current situation of telecommunication ministry of Afghanistan. Section IV indicates the methodology of choosing and modeling the proposed/ recommended migration strategies. The recommended migration strategy process is included in Section V. Finally, the paper concludes in Section VI.

\section{LITERATURE REVIEW}

The aim of this study is to develop a cloud migration strategy model from studying the migration strategies that exists and are getting used in common and effectively and recommend the model to communication and information technology ministry of Afghanistan to fit their current IT, services and infrastructure situation.

Government acceptance of cloud computing has been growing fast. (Zhao, Gaw, Bender \& Levy, 2018) lists 10 benefits of cloud computing on e-government, such as rapid scalability, low maintenance/upgrades cost, improved resource utilization, improved economies of scale, improved collaboration capabilities, usage-based pricing, reduced IT infrastructure needs, computational power, greenfriendly factor, and improved disaster recovery capabilities.

It is important to bear in mind that "cloud computing is a tool, not a strategy" (Wyld, D. C. 2010), Government IT leaders thus will be well-advised to take a programmed assessment of how cloud computing can fit into their overall IT strategy, in support of the mission and overall strategy of their agency. This should take a six-step process, as shown in Fig. 2.

Migration to the cloud refers to the process of moving applications, data, servers, networks from inpremises to the cloud data centers. This migration of ICT to the cloud can be conducted partially on some systems of the organization. Alternatively, All the IT infrastructure can be migrated to the cloud (Alharthi, A., Alassafi, M. O., Walters, R. J., \& Wills, G. B. 2017)

(Upadhyay, N. 2017) has proposed a systematic QoS evaluation and ranking framework for cloud services. The proposed framework is computationally effective, easily manageable and flexible to consider multitude of qualitative and quantitative data for the evaluation and ranking of cloud services.

(Fahmideh, M., Daneshgar, F., Rabhi, F., \& Beydoun, G. 2018) has introduces a metamodel instantiation for the creation of situational methods involves some factors such as the choice of a target cloud platform, the pricing model of cloud providers, and characteristics of the development team and insisted that making trade-offs among these factors that sometimes contradict or depend on each other has an impact on the meta-model instantiation and specialization.

(Jamshidi, P., Ahmad, A., \& Pahl, C. 2013) identified a need for a concrete migration framework to enable systematic migration to the cloud. The study indicated that crosscutting concerns are not adequately addressed. It also observed a lack of tool support for enhancing cloud migration.

\begin{tabular}{|c|c|}
\hline Step & - Learning \\
\hline Step & - Assissing the current situation \\
\hline Step & - Cloud Pilot \\
\hline tep & - Assessing the readiness of the cloud invironment \\
\hline tep & - Cloud development plan \\
\hline Step & - Impoving the cloud stably \\
\hline
\end{tabular}

Fig. 2. The Six-Step Cloud Migration Strategy 
In reference [24] the author introduces a generic, model-driven, platform independent process model that will help the different stakeholders in the enterprise to take a systematic approach in their journey towards cloud migration. It does so by ensuring both IT and business experts work collaboratively in an efficient manner to avoid potential pitfalls.

In (Zalazar, A. S., Gonnet, S. M., \& Leone, H. P. 2015) paper, presented a preliminary workflow to perform the migration of legacy systems, which consists of 13 steps. The proposed approach has been developed using in system migration project and the deep analysis of Cloud Computing characteristics and represented a useful and simple tool for decisions making, project organization, and tasks planning for Cloud Computing projects.

REMICS (REuse and Migration of legacy applications to Interoperable Cloud Services) is a research project supported by the European Commission that started in 2010 and will run for three years. The project's main objective is to develop a set of model-driven methods and tools that support organizations with legacy systems to modernize them according to the "Service Cloud paradigm" (Mohagheghi, P. 2011).

The cloud computing paradigm enhances thinking of IT companies as service providers. Therefore the research indicates the "Service Cloud paradigm" that stands for the combination of cloud computing and Service-Oriented Architecture (SOA) for the development of SaaS systems (Mohagheghi, P. 2011).

(Wyld, D. C. 2010) shows the importance of the cloud and the way internet changes to the cloud services soon in 2020 as in Fig. 3.

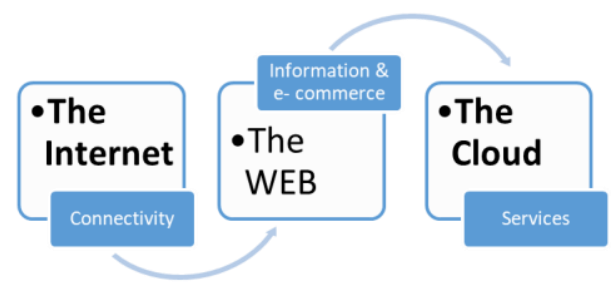

Fig. 3. From the Internet to Cloud Computing

The reference [22] the framework and its way of implementation shows a decent model driven method to migrate the legacy application into the cloud environment which includes all steps of the migration process and provides a concise framework to support overall process for migration.

\section{AFGHANISTAN COMMUNICATION \& IT MINISTRY'S CURRENT SITUATION}

To understand what cloud strategies businesses are adopting and where they plan to take them in future, it is essential to look at where they are now [19], therefore in this section of the research it is intended to observe and verify current situation in Afghanistan's communication and information technology Ministry.

Cloud computing holds a number of advantages such as "reduced cost, increased storage, higher levels of automation, increased flexibility, and higher levels of employee mobility" for the government (Wyld, D. C. 2009).

Significant progress has been made to promote e-

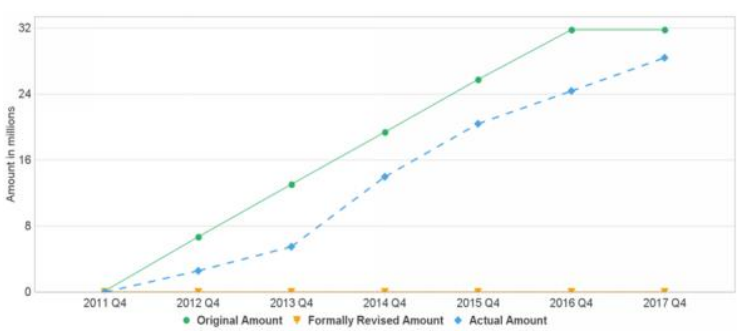

Fig. 4. Afghanistan ICT sector project development Government, but more efforts are required to establish the critical e-Government foundations and to deliver prioritized e-services by MCIT in Afghanistan [28].

The communication and IT ministry was started to work in 1955, the time which just the wired one to one telephone network was being experienced in the field, later they improve these to the telephone telecommunication system. Not after a while the ministry provided the telegraph services through a huge step development in that time. This approach was the only sole source in the new era of communication facilities provided for the people and the government itself.

In 1928, one of the most popular achievements of country was getting the membership of the International Telegraph Union (ITU) through that the country could benefit from the communication facilities.

An international radio transceiver was installed in mid 1960s in capital city Kabul which connected the country to the world.

The private sectors get in work and encouraged by the government after 2001 to invest in different fields such as telecommunication by the time interim government was organized by the elected government. Therefore there was lots of communication services 
provided by the private sector including the information technology services.

All private sector companies are enabled by the ministry of communication and information technology's policies and strategies to invest in the field of communication and provide better services of information technology.

Providing high quality communication, information technology and postal services for all people in a lower and affordable price is the mission of the ministry. Stablishing a consistent and democratic politic environment, the rule of law and a suitable regulatory environment for business is the goals for the government.

The vision of the Ministry of Communication and IT is to transform Afghanistan into Information Society [12].

Afghanistan MCIT has been vastly developing from 2001 till 2017 in a positive way increasingly as

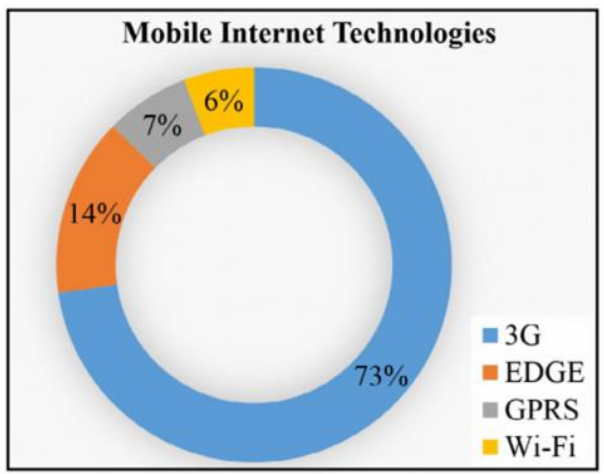

Fig. 5. Mobile internet technologies in Afghanistan

shown if Fig. 4. [25] MCIT provides internet around all regions of Afghanistan mostly through mobile telecommunication services by telecommunication companies such as Roshan, Afghan wireless, Etisalat, MTN, Salam and Afghan telecom. The mobile internet technologies defer from region to region in Afghanistan such that starts from GPRS, EDGE and $3 \mathrm{G}$ mobile internet services to WIFI services as shown in the Fig. 5. And newly just the private telecommunication companies are providing $3.75 \mathrm{G}$ near 4G internet services. (Habibi, M. A., Ulman, M., Baha, B., \& Stočes, M. 2017).
According to MCIT, out of Afghanistan's 34 provincial capital cities, 25 have been connected to the OFC. Currently, Afghanistan's only neighbor that is not connected through fiber is China as in Fig. 6. In September 2017, the intention to connect China and Afghanistan through the Wakhan Corridor was confirmed as part of a broader Memorandum of Understanding signed between China Telecommunications Corporation and Afghan Telecom. The Memorandum of Understanding focuses on jointly promoting the construction of the Silk Road Cable System with an objective to promote connectivity and cooperation between Eurasian countries under the overall objectives of the Belt and Road Initiative led by China [27].

Afghansat is the satellite by which the government of Islamic republic of Afghanistan provides services through ministry of communication and information technology which indicates Afghanistan's entry into the commercial satellite business. Afghansat provides a significant number of services consisting broadcasting, mobile telephony backhaul and IP connectivity. MCIT also agreed on exploring opportunities for longer-term cooperation with Eutelsat [28].

MCIT provides e-Government and the egovernment includes the services and projects such as e- Health (Telemedicine), e- Education (schools \&

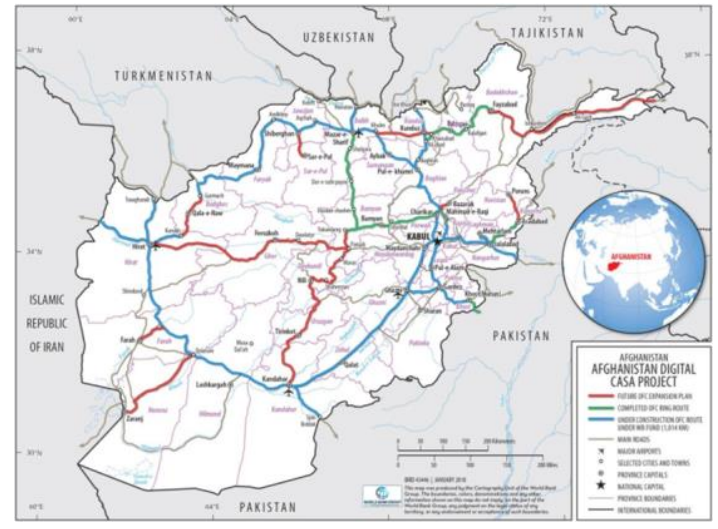

Fig. 6. OFC Networks

Universities), Public awareness (Capacity building), EGovernment Resource center (Consultancy, Audit, eServices), Incubator Management, Afghanistan websites, E-Document Management System, EDocument Management System, 5 GSM operators With 3G services (Roshan, Etisalat, AWCC, MTN, Afghan telecom), Fiber optic connectivity, e-Tazkara (e-NID), Satellite, Afghanistan portal and eGovernment complex (one Stop shop) [29]. 
Afghanistan MCIT has a national Data center called Afghan National data center (ANDC) which is providing services partly in capital city (Kabul).

\section{METHODOLOGY}

In contrast to a non-structured review process, a systematic literature review reduces bias and follows a precise and accurate sequence of methodological steps to research literature. The methodology of this research is based on the stages below:

a) To identify the amount of researches done on cloud migration strategies processes and models to find the most commonly used cloud migration strategies.

b) Clarify the readiness of MCIT Afghanistan and what is going to be migrated to the cloud.

c) Study feasibility of strategies on the MCIT Afghanistan.

d) Select and justify a cloud migration strategy from the reviewed strategies in the literature section and verify the cloud migration strategy that fits to the current situation of MCIT of Afghanistan.

e) Implement the cloud migration strategy. In this research totally 20 related research papers

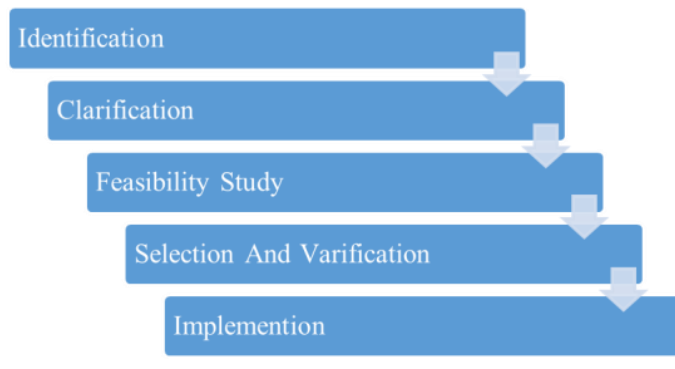

Fig. 7. Methodology

reviewed and found most commonly used migration strategies cited. On the other hand the readiness of the on- promise (ministry of communication and IT) is studied and clarified the services by online interviewing with cloud migration project officer at MCIT the interview questions are appended at the end of the research paper in Appendix one, platforms and infrastructures to be migrated to the cloud, then the matching phase which shows if the reviewed strategies can be feasible or not to the current situation of MCIT. After finding the feasibility of the strategies on MCIT then the selection of the migration is done after all the selected migration strategy would be ready for implementation as shown in Fig. 7.

\section{RECOMMENDED MIGRATON STRATEGY}

It leaders should recognize that there are eight fundamental elements that are vital in enabling the cloud computing concept. As shown in Fig. 8. For the cloud model in the public or private sector (Wyld, D. C. 2010). Universal Connectivity (users must have near-ubiquitous access to the internet), Open Access (users must have fair, non-discriminatory access to the internet), Reliability (the cloud must function at levels equal to or better than current standalone systems), Interoperability and User Choice (users must be able to move among cloud platforms), Security ( users' data must be safe), Privacy (users' rights to their data must be clearly defined and protected), Economic value (the cloud must deliver tangible savings and benefits) and Sustainability (the cloud must raise energy efficiency and reduce ecological impact) as shown in Fig. 8.

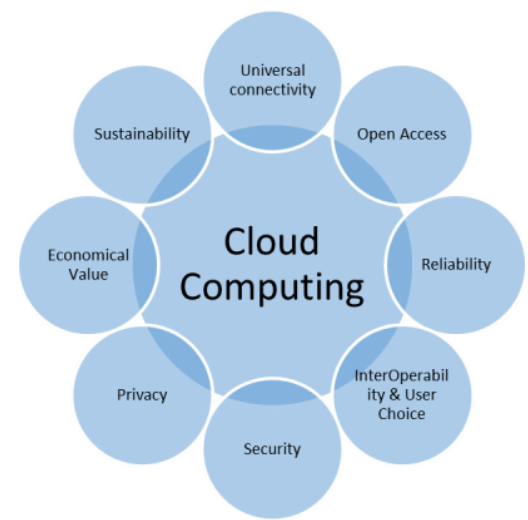

Fig. 8. The 8 Fundamental Elements of Cloud Computing

MCIT is now on the initial phase of Information technology MCIT is now on the initial phase of Information technology involving infrastructure and services and now in near times it's providing $3 \mathrm{G}$ internet via fiber optic on central regions of some province and regions.

MCIT with the infrastructures, network systems and the services which provides is not completely ready for migrating to the cloud because of lack of the high speed internet and IT specialist but it will be better to start getting ready for migration. At least at this time it's possible to migrate to migrate just MCIT's IT infrastructure on the cloud environment and MCIT can migrate the data center at this time but after fulfilling the readiness phase it can totally get migrated to the cloud environment.

In part of research it is intended to introduce a cloud migration strategy for whole MCIT migration to cloud environment. 


\section{International Journal of Engineering Applied Sciences and Technology, 2020 Vol. 5, Issue 4, ISSN No. 2455-2143, Pages 73-81 \\ Published Online August 2020 in IJEAST (http://www.ijeast.com)}

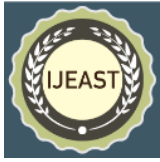

\begin{tabular}{cl}
$\begin{array}{c}\text { Migration } \\
\text { factors }\end{array}$ & \multicolumn{1}{c}{ Consideration } \\
$\begin{array}{c}\text { Business } \\
\text { impacts }\end{array}$ & $\begin{array}{l}\text { Assets that have high business impact } \\
\text { should normally be spread over multiple } \\
\text { packages to reduce risk. } \\
\text { Depending on the size of the outage and } \\
\text { the number of resources available, size } \\
\text { and composition of a package can be } \\
\text { constraints }\end{array}$ \\
$\begin{array}{l}\text { limited. } \\
\text { Physical }\end{array}$ & $\begin{array}{l}\text { If the source data center has } \\
\text { environmental issues like (overheating), } \\
\text { components that provide the quickest } \\
\text { relief should be a priority in early } \\
\text { package. } \\
\text { The value of the components being } \\
\text { and risk }\end{array}$ \\
$\begin{array}{l}\text { moved maybe a consideration for } \\
\text { insurance coverage and risk. }\end{array}$ \\
Personnel & $\begin{array}{l}\text { Consideration must be given to avoid } \\
\text { overtaxing resources. }\end{array}$
\end{tabular}

Table 1 (Migration Packaging Considerations)

The recommended migration strategy includes 3 main stages of pre- migration, migration and post migration [33] shown in Fig. 9. Which is briefly explained below:

a) Pre-Migration stage: in this stage the MCIT may consider to have a clear vision which shows where the IT and business would overlap in the future, should train staffs expertly early while migrates to cloud environment, should know which assets they have [32] and selecting a good partner helps more along the migration stages.

b) Migration stage: After getting ready for migration MCIT can migrate the prepared assets in the stage. The migration stage can be separated in to 3 sub-stages (packages) to migrate safely and quickly, by separating migration stage into three sub-stages the assets can be packaged three times and every time a group of assets packages can be migrated such that infrastructure, services and platforms considering the following (table 1) migration packaging considerations and factors:
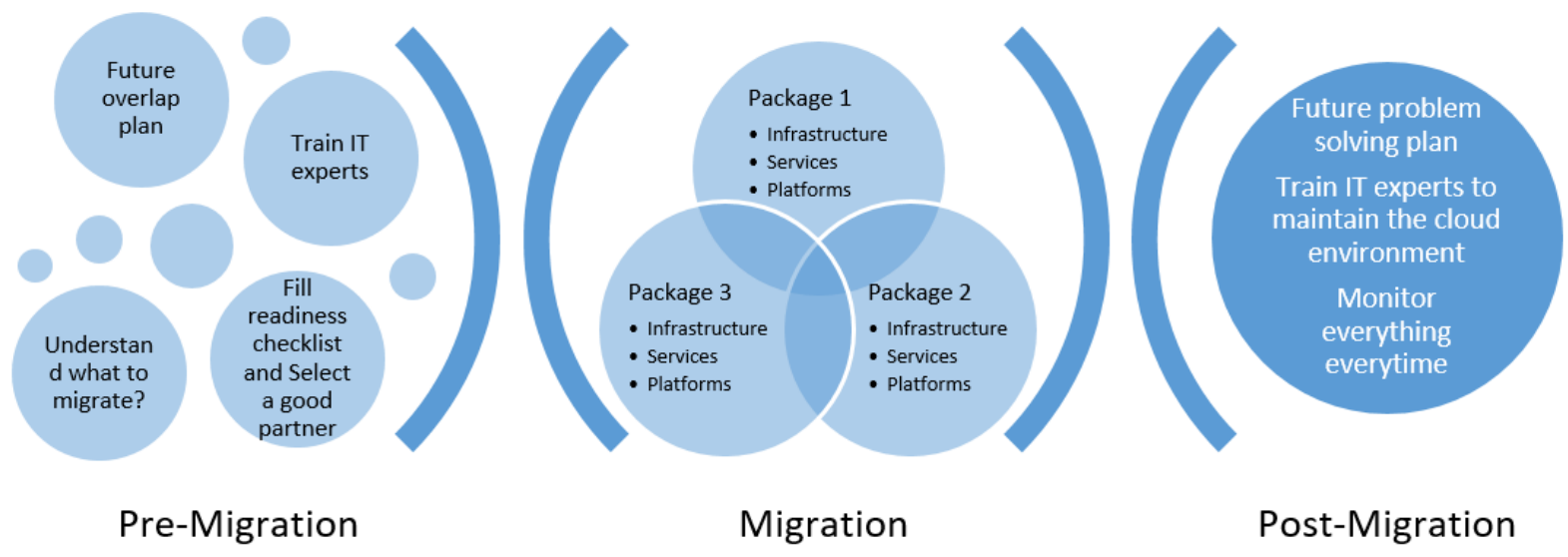

Post-Migration

Fig. 9. Migration strategy stages

c) Post-Migration stage: in this phase MCIT should have a plan for future to prevent or resolve the problems such as performance issue, data loss, and/or security breach or at least one outage [31] and must have train some IT specialists on how to quickly get to root cause and resolve the issue or the MCIT can use the latest DevOps- is a set of practices intended to reduce time between committing a change to a system and the change being placed into normal production, while insuring high quality- [30] principles around continuous integration/ continuous deployment. And MCIT rather to pay attention on monitoring everything to see how the environment is preforming and test all application.

\section{CONCLUSION AND FUTURE WORK}

Afghanistan MCIT would be ready to migrate their national data center to cloud environment by the strategy given in this research letter on getting totally ready and train IT specialists in the field they would migrate their applications and services too. In this paper it is intended to produce a cloud migration strategy by studying the related works done on this field, so that fits to the current situation of Afghanistan's MCIT. In this paper it's tried to give some introduction on cloud computing, cloud migration and cloud computing services at the beginning, later on so many research papers are summarized and listed as related works after that the current situation of MCIT is studied deeply from online sources and online interviews to data center manager of MCIT proceed by a brief methodology. 


\section{International Journal of Engineering Applied Sciences and Technology, 2020 \\ Vol. 5, Issue 4, ISSN No. 2455-2143, Pages 73-81 \\ Published Online August 2020 in IJEAST (http://www.ijeast.com)}

This paper would be a better reference for the ones who want to research on migration of their organization in Afghanistan regions.

\section{ACKNOWLEDGMENT}

The authors wish to express their gratitude to computer science faculty of Balkh University and Bakhtar University for providing the safe and sound research environment to fulfill the research work. Also the authors would like to extend their gratefulness to Ministry of communication and IT Afghanistan (MCIT) and Afghanistan National Data Center (ANDC).

\section{REFERENCES}

1. Alharthi, A., Alassafi, M., Walters, R., \& Wills, G. (2016). Towards a framework to enable the migration process to educational clouds in Saudi higher education.

2. Khadija SABIRI, Fouzia BENABBOU, Hicham MOUTACHAOUIK, and Mustapha HAIN, (2016). Toward a Cloud Migration Framework.

3. Balasubramaniam, Deepa. (2018). A Review on Cloud Computing. 4. 197-199.

4. Alharthi, A., Alassafi, M. O., Walters, R. J., \& Wills, G. B. (2017). An exploratory study for investigating the critical success factors for cloud migration in the Saudi Arabian higher education context. Telematics and Informatics, 34(2), 664678.

5. Gholami, M. F., Daneshgar, F., \& Rabhi, F. (2016). Cloud migration: methodologies: preliminary findings. In European Conference on Service-Oriented and Cloud ComputingCloudWays 2016 Workshop.

6. Zhao, F., Gaw, S. D., Bender, N., \& Levy, D. T. (2018). Exploring Cloud Computing Adoptions in Public Sectors: A Case Study. GSTF Journal on Computing (JoC), 3(1).

7. Alzoubaidi, A. R. (2016). Multi-campus universities private-cloud migration infrastructure. International Journal on Cloud Computing: Services and Architecture (IJCCSA), 6(3), 1-13.

8. Kesavulu, M., Bezbradica, M., \& Helfert, M. (2017, April). Generic Refactoring Methodology for Cloud Migration Position Paper. In International Conference on Cloud Computing and Services Science (Vol. 2, pp. 692-695). SCITEPRESS.

9. Regina Au, (2016), To Cloud Compute, or Not to Cloud Compute? p. 2.

10. http://www.whymeridian.com/blog/bid/341364/ Clarity-on-the-Cloud-defining-private-public- hybrid-and-community-clouds, retrieved on 20 Nov 2018.

11. Aslam, M., bin AB Rahim, L., Watada, J., \& Hashmani, M. (2018). Clustering-Based Cloud Migration Strategies. Journal of Advanced Computational Intelligence and Intelligent Informatics, 22(3), 295-305.

12. https://mcit.gov.af/about-ministry, Communication \& IT ministry of Afghanistan, retrieved on 19 Nov 2018.

13. Upadhyay, N. (2017). Managing Cloud Service Evaluation and Selection. Procedia computer science, 122, 1061-1068.

14. Fahmideh, M., Daneshgar, F., Rabhi, F., \& Beydoun, G. (2018). A generic cloud migration process model. European Journal of Information Systems, 1-23.

15. Jamshidi, P., Ahmad, A., \& Pahl, C. (2013). Cloud migration research: a systematic review. IEEE Transactions on Cloud Computing, (1), 1.

16. Zalazar, A. S., Gonnet, S. M., \& Leone, H. P. (2015). Migration of Legacy Systems to Cloud Computing.

17. Pahl, C., \& Xiong, H. (2013, September). Migration to PaaS clouds-migration process and architectural concerns. In Maintenance and Evolution of Service-Oriented and Cloud-Based Systems (MESOCA), 2013 IEEE 7th International Symposium on the (pp. 86-91). IEEE.

18. Alzoubaidi, A. R. (2016). Multi-campus universities private-cloud migration infrastructure. International Journal on Cloud Computing: Services and Architecture (IJCCSA), 6(3), 1-13.

19. https://dzone.com/articles/the-next-generationof-cloud-computing, white paper provided by Microsoft, retrieved on December 8, 2018.

20. Mohagheghi, P. (2011). REMICS-REuse and migration of legacy applications to interoperable cloud services.

21. Wyld, D. C. (2010). The cloudy future of government IT: Cloud computing and the public sector around the world. International Journal of Web \& Semantic Technology, 1(1), 1-20.

22. Menychtas, A., Santzaridou, C., Kousiouris, G., Varvarigou, T., Orue-Echevarria, L., Alonso, J., ... \& Pellens, B. (2013, September). ARTIST Methodology and Framework: A novel approach for the migration of legacy software on the Cloud. In 2nd Workshop on Management of resources and services In Cloud And Sky computing (MICAS 2013). 
23. Wyld, D. C. (2009). Moving to the cloud: An introduction to cloud computing in government. IBM Center for the Business of Government.

24. Ramalingam, A. B. Master Thesis No. 3348 Cloud Migration-a Reference Process Model.

25. The World Bank: Afghanistan ICT sector project development (implementation status and result report). 30 June 2017.

26. Habibi, M. A., Ulman, M., Baha, B., \& Stočes, M. (2017). Measurement and Statistical Analysis of End User Satisfaction with Mobile Network Coverage in Afghanistan. arXiv preprint arXiv: 1706.06933.

27. Afghanistan - Digital Central Asia South Asia (CASA) Project: Project Appraisal Document. March 28, 2018 available online:

28. https://www.gtai.de/GTAI/Content/DE/Trade/Fa chdaten/PRO/2018/04/Anlagen/PRO2018041950 02.pdf? $\mathrm{v}=1$

29. Available online,

https://www.eutelsat.com/en/news/press-

releases/2014/afghanistan-signs-partnershipwith-Eutelsat.html retrieved on 10 December 2018.

30. SESSION-

1_Afghanistan_Mr_Hidayatul_Haq_Hidayat.pdf available online. Retrieved on 10 December 2018.

31. Loukides, M. (2012). What is DevOps? "O’Reilly Media, Inc.".

32. https://www.linkedin.com/pulse/what-happensafter-cloud-migration-todd-osborne/ retrieved on 12 December 2018.

33. https://medium.com/aws-enterprisecollection/21-best-practices-for-your-cloudmigration-e406546cb66b retrieved on 12 December 2018.

34. An application-centric approach to data center migration: white paper. Dell ecm. available online: https://www.emc.com/collateral/whitepapers/h6151-ep-application-centric-approachto-data-center-migration.pdf 